\title{
基于中学生整本书阅读指导策略研究
}

马小红

阿勒泰市第一中学

DOI:10.32629/er.v3i1.2390

[摘 要] 阅读是伴随一个人成长的良好生活习惯,对人的发展有着极为显著的影响。在中学语文教学工作中,教师科学、有效的引导学生进行 整本书阅读,更是语文教学工作中不可或缺的重要环节。在不断的学习和发展中, 学生接触的阅读文章难度和篇幅都将有明显增加, 这也需要适 当延长阅读时间, 在某种程度来说, 这也是对学生耐心和理解能力的重要挑战。基于此, 本文将以中学生作为研究基础,进一步分析中学生的整本 书阅读指导策略, 希望对学生综合素质提升和语文能力提升提供重要帮助。

[关键词] 中学生; 整本书阅读; 阅读指导

新课标已经对课外教学提出了明确建议, 要求教师在教学工作中要着 重对学生的阅读兴趣进行培养, 在扩大阅读面的基础上, 增加学生的阅读 量, 多读书、读好书, 鼓励和引导学生自主进行阅读材料的选择。那么针对 这一建议, 中学教师应该怎样引导和帮助学生开展整本书阅读呢? 下文将 对这一问题展开详细探究。

1 加强对学生阅读能力的提升,在拓展视野的基础上激发学生阅 读积极性

不管开展何种类型的指导工作, 都需要以学生自主性作为基础, 让学 生愿意并且主动参与到阅读过程中, 之后才能对其指导问题进行探究。在 教育心理学角度上说, 兴趣主要是一个人认知、研究得到知识的典型心理 特征, 有助于推动人们求知的一种全新力量 ${ }^{[1]}$ 。学生只有对某一学科产生 学习兴趣, 才能对这一学科投入更多精力, 在不断的钻研和学习过程中实 现学习效率的提升。单纯从学习推动性上分析, 兴趣的提升是学生学习的 主要动力因素。兴趣本身就是在学习活动中产生, 并且兴趣在学习结果中 的作用多为积极性。因此, 在阅读活动指导过程中对学生阅读兴趣进行激 发也是一项基础性工作。

\section{2 适当鼓励,强化学生的学习动力}

在教学工作开展中, 鼓励是最关键的教育教学手段, 尤其是在构建民 主课堂的教学氛围中, 对学生进行适当鼓励可以更有效的帮助学生实现潜 能发挥。在实践中发现, 适当、合理的鼓励方式可以获取更为显著的教学 成果。对学生的鼓励主要具备三方面优势: 首先, 充分调动学生的主观能 动性, 推进学生学习积极性的提升, 帮助学生提升自信心 ${ }^{[2]}$ 。其次, 对中等 生而言, 教师的鼓励就如同航海中出现的灯塔, 不仅能帮助学生更精准的 掌握学习方向, 还能帮助学生实现学习积极性的提升。比如学生在开展整 本书阅读的过程中, 经常会因为文章的圥长产生负面情绪, 甚至对阅读产 生排斥感, 在这一过程中教师就需要适当鼓励和引导学生, 对学生已经阅 读完的部分给予肯定, 鼓励学生继续探索后面的内容。最后, 教师对后进生 的鼓励对学生而言就如同清晨的露水一样宝贵, 所以教师也要掌握正确的 鼓励时机, 通过适当鼓励帮助学生更新自我认知, 在转变传统学习观念的 基础上, 为今后学习方向的明确奠定良好基础。

\section{3 在科学指导过程中,提升阅读效率}

通过对实践教学的研究发现, 在整本书阅读指导工作开展中, 部分教 师仍然存在过度干预或是干预力度不足的情况, 因而阅读工作中对学生的 合理指导也应该是当前最需要关注的问题。在教学工作中, 一些教师考虑 到学生自主学习的效果不够显著, 所以急于对学生进行知识的指导和传授, 此种情况下就会出现教师在课堂中的一味讲解, 学生被动接受知识的情况 ${ }^{[3]}$ 。我们都知道, 学而不思则罔, 思而不学则殆, 因此学习和思考应该共同
进行, 不能出现分割的情况, 这种情况下很可能会对学生的思维发展造成 限制性影响。还要一种情况就是学生在发表自身想法后, 教师会在第一时 间进行纠正, 这也是干预性不够的重要表现。教师在实践工作中应该始终 将学生为主体作为课堂教学基础, 但是很多教师忽视了自己在课堂中的引 导性作用, 此种情况下只能任由学生在课堂中天马行空, 教师很难实现对 学生思维的有效掌握。因此, 教师指导程度是否合理也将课堂教学工作的 开展产生直接影响, 在对学生进行整本书阅读指导的过程中也要对这一问 题进行关注。

\section{4 构建科学的教学指导计划,帮助学生实现阅读习惯的培养}

青少年阶段是每个人成长和发展的关键阶段, 所以也是对学生阅读习 惯和品质养成的关键时期。教师在对学生整本书进行阅读指导的过程中, 不仅仅是要帮助学生增长知识, 还需要在阅读过程中帮助学生掌握各种阅 读规则, 在养成阅读习惯的基础上, 为学生语文素养的提升奠定良好基础。 在教学工作中, 帮助和引导学生制定健全的阅读计划, 时间一长, 学生就会 在无形中将这种习惯转变为自然, 这对于学生的综合发展也将起到更为显 著的积极影响 ${ }^{[4]}$ 。比如在日常生活中, 教师可以要求学生每周或是每个月 保证读够几本书, 主要进行那几本书的阅读, 怎样阅读等等都需要教师帮 助学生制定合理性计划, 此外, 在阅读过程中也要引导学生加强对读书笔 记的记录, 从而对读书笔记进行科学分类, 帮助学生更精准的掌握和理解 阅读内容, 实现阅读能力和水平的稳定提升。

\section{5 保证阅读指导和语文常识之间的统一}

在阅读指导工作的开展过程中, 要掌握一个科学的 “度”, 保证阅读指 导工作的开展能有效满足语文教学常识要求。整本书阅读指导是当前语文 教学的重要组成环节, 因此也是教学工作中最需要遵守的语文教学原则。首 先, 在教学工作中应该发挥体验原则的优势 ${ }^{[5]}$ 。教师应该对学生真实的审 美体验进行关注, 指导和帮助学生进行阅读, 只有学生真正融入到阅读中, 才能在阅读之后, 读出自己最真实的体验。其次, 要切实发挥对话原则的优 势作用。对话离不开话题, 整本书的阅读话题, 指的就是阅读交流的角度, 因此教师在教学工作中更应该精心设计, 只有这样才能保证学生在阅读过 程中产生更合理的话题。

\section{6 效果评价,以评促读}

学生学习效果要借助评价方式进行展现, 所以只有对结果的检测性进 行掌握教师才能更准确的进行教学效果和方法的调整。对于很多学生而言, 学习目标主要是教师评估后的结果决定, 所以教师的评估往往也会对学生 的成绩起到一定影响作用。总而言之, 无论是课堂阅读教学还是课后的整 本书阅读, 都应该对教学的效果进行评价, 只有这样才能在调整教学方向 的基础上, 更好的推进阅读工作的开展。 


\title{
浅析农场档案管理规范化工作
}

\author{
王海霞 \\ 黑龙江省梧桐河农场劳资科 \\ DOI:10.32629/er.v3i1.2409
}

[摘要] 随着农场的发展建设,农场的档案管理工作也发生着变化,人员与工作流程的增加使档案管理的内容在丰富的同时, 也造成相对的混乱, 为促进农场的快速发展。目前的档案工作正处于从封闭型管理到开放式服务, 从人治到法治、重保管到重服务、传统管理到现代化管理的转型 期,档案管理的规范化是现代化管理的重要内容,本文主要从实现档案管理的规范化进行对策分析。

[关键词] 农场; 档案管理; 规范化工作

档案就是指过去和现在的国家机构、社会组织以及个人从事政治、军 事、经济、科学、技术、文化、宗教等等活动直接形成的对国家和社会有 保存价值的各种文字、图表、声像等等不同形式的历史记录。档案是保存 备查的文件: 档案的形式是指档案的载体形态和记录与表达方式: 档案是 人类社会活动的原始记录, 档案是人类社会实践活动中形成和产生的各种 材料转化而来的, 不是事后另行随意编写和随意收集而来的。

\section{1 农场档案进行规范化管理的必要性}

农场在创新发展、现代农业发展建设以及生产经营管理等方面的重要 举措, 都产生了重要的档案资料, 真实记载了农场的发展变化, 农业生产工 作和种植发展情况, 为农场农业的科学研究提供了依据, 也为广大种植户 的权益提供了重要保障。这些年, 农场在各个领域形成的档案资料不少, 也进行了档案的归档收集, 但是随着现代化发展的进程, 档案管理也面临 着改革发展, 从目前农场档案管理来看, 还存在着很大差距, 现有的档案管 理经验式的管理居多, 与其他先进单位相比, 需要完善的东西还很多, 尤其 是现代农业的发展需要, 我们现有的档案管理与现代的快捷方便、管理规 范和立卷标准等档案管理差距很大, 有些单位的档案还保留在业务部门工 作人员手中, 尽管农场都有档案室, 但在收集保管的档案类别上还有待创 新, 还需开拓性思维, 跟上农场现代快速发展的需要, 在财务档案、文书档 案、人事档案的基础上, 结合农场现有工作内容和发展方面, 进行规范化管 理, 使农场档案达到标准化要求是必要的。

\section{2 农场档案管理规范化管理的主要内容}

2. 1加强领导管理。档案管理涉及到相关工作的各个环节, 不管是资料 的存储, 还是信息的查询, 都需要建立严格的档案管理系统, 从而提升整个 部门的运营效率, 农场档案工作更是如此, 需要将重要的事宜提上日程, 加 强领导的重视力度及管理力度。对待重大问题应采取一定的形式予以讨论 并解决, 并结合实际整改效果分析及制定下一步计划。档案领导工作应覆 盖各个环节, 对相关岗位负责人明确工作内容及职责范围, 从而促进工作

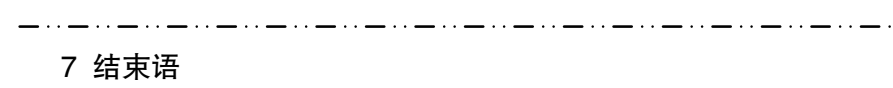

综上所述, 对中学生开展整本书阅读指导, 不仅需要教师自身具备较 强的阅读能力, 还需要教师在阅读教学过程中与学生共同开展阅读内容的 探索, 只有这样才能确保学生更深刻和全面掌握书本内容。在研究中发现, 当前中学生阅读教学工作仍然存在很多问题, 所以为了切实提升学生的语 文能力, 教师更应该加强对此种教学方法的探索和完善, 在对内容实现条 理化构建的基础上, 帮助和引导学生参与到阅读工作中, 最终为学生语文 阅读水平和文化素养的提升奠定良好基础。

[参考文献]

[1]王太华.农村中学语文整本书阅读教学策略 [J]. 魅力中
流程的规范化。

2. 2 健全网络组织系统。社会经济的快速发展使得各类信息量飞速增 加, 为了适应工作的需求, 应对档案管理工作不断改进, 从观念上、制度上、 人员分配及技术手段上进行技术性更新, 并逐步实现信息化的管理模式。 首先从硬件配备上应保证相关设施运转顺利, 并保证系统的安全可靠, 安 排好日常管理人员做好定期的维护工作, 进而提升办公效率, 实现农场档 案工作快速发展。

\section{3 农场档案管理现状}

农场一般都设有档案管理室, 主要包括科技档案、专门档案、文书档 案等, 加强档案管理, 保证农场档案管理规范化、科学化至关重要, 但是当 前, 农场档案管理现状不容乐观, 主要存在以下几点问题:

3.1 档案管理人员的综合素质有待提高, 当前, 档案管理人员综合素 质普遍不高, 再加上档案部门对档案管理人员的要求较低, 档案管理人 员只需要具备一定的知识文化即可, 对档案管理人员的档案收集与管理 能力、档案管理知识都不做要求, 致使档案管理人员综合能力较差, 管理 水平不佳。

3. 2 档案室建筑面积较小, 可以存放的档案资料有限, 无法保证档案资 料的质量与数量, 容易出现档案资料不全问题, 为档案的规范化管理造成 阻碍。

3. 3 档案信息化工作落实不到位, 刚刚起步, 档案管理工作需要结合先 进技术, 加大研究力度, 实现档案的信息化、规范化管理, 但是当前, 档案信 息化工作落实效果不佳, 无法提高档案管理水平, 影响了档案管理工作的 开展实施。

3.4 农场档案部门的硬件设施仍需加强, 缺乏计算机、档案柜等专用工 具, 基础设施建设不足, 档案管理工具陈旧。

4 实现农场档案管理规范化的措施

4. 1 加强档案管理人员业务素质和工作技能培训。要强化档案管理队 